\title{
ARCHITECTURES OF CRISIS IN BLINDESS AND SYNECDOCHE, NEW YORK
}

\author{
By May Chew
}

This paper endeavours to do two things at once. It posits, firstly, that Fernando Meirelles's Blindness (2008) and Charlie Kaufman's Synecdoche, New York (2008), can be conceptualized through the language of crisis and quarantine, in order to illustrate how architectural and discursive enclosures - or the synchronized acts of building and narrating crisis - work to anxiously "contain the outbreak" and regulate the wayward text or body. At the same time, this paper also looks at the ways in which Synecdoche, when compared to the more prototypical quarantine film, Blindness, is in the end rather ambivalent with regards to the disciplinary project of quarantine, and in fact leaves room for unresolved tensions and renegade narratives which function to significantly trouble the articulation and containment of crisis.

Blindness, an adaptation of Jose Saramago's 1995 novel, deals with the epidemic of blindness which, over the course of a single night, afflicts the citizens of a nameless city. The scale of the crisis here is all-encompassing; the loss of vision, and, one could argue, the loss of one's ability to consume and partake in Debordian spectacality, results in the suspension of social, legal, state, and symbolic orders, leading to mass societal breakdown. Initial groups of the infected are quarantined en masse by government agents in hopes of containing the disease; however, the contagion spreads and the world both inside and outside the quarantine slowly disintegrates into bedlam. Synecdoche, by contrast, explores considerably more intimate calamities: namely, its protagonist's abundant bodily and narrative failures. The movie centers on Caden, a theatre director plagued by his ailing body, a crumbling marriage, profound loneliness, and endless preoccupations with death. After receiving a MacArthur Genius Grant - awarded to him right after he is abandoned by his wife and daughter - Caden sets out to 
mount his greatest and "truest" masterpiece yet: a simulacrum of his world populated by a cast of thousands, in an exact replica of New York City, all magnificently housed inside an abandoned warehouse in the city's theatre district. The principal difference between these two films is that, while Blindness centres on the lauded function of the quarantine to successfully sublimate crisis, and clear the way for the return to an effectively untraumatized "normal," Synecdoche, on the other hand, challenges precisely these enclosures that Caden himself so meticulously constructs.

A number of theorists have argued about the generative potential of crisis to facilitate movement, renewal, and change (Bono and Giardini; Zamora). However, this sanguinity effectively glosses over the disciplinary corollary of crisis, which often seeks to manage and sublimate chaos/multiplicity/alterity through enclosure, and the reassertion of narrative authority. In architectures of containment, which are doubly structured so as to prevent entry as well as exit, borders understandably become perilous terrains, wherein the threats of cross-contamination necessitate the exercise of violence. The "hospital" into which the infected are horded in Blindness, is a benevolent term for a violent penal quarantine patrolled by armed guards who don't hesitate to pull the trigger at anyone who fails to "stay in line." Narrative control, in much the same way, is asserted in order to reign in otherness and iterate the self as a singular and coherent subject. Caden's warehouse, as well as the hospital for the blind, both reflect this crafting of crisis onto a single site or into a single story, so that its borders can be efficiently patrolled. Thus, we see that in the "singular" moment of quarantine—singular precisely because it is presented as hermetically contained — the outside world is often rendered empty or bereft. In Blindness, the doctor's wife (a nameless foil portrayed in the film by Julianne Moore) attempts to get a hold of someone - anyone — on the emergency phone to ask for medical supplies when the wound of another internee becomes fatally infected. To her mounting 
frustration, there is never a voice on the other line. Here, the silence punctuated by the dead line serves as nothing more (and nothing less) than a pointed reminder that, in times of crisis, any form of exchange must necessarily be suspended, lest it belie the porousness of containment architectures.

\section{Crisis Building}

The following sections look at the twin projects of crisis building and crisis writing and explore further how these two films diverge drastically in their approaches. When we speak of "building," it is with specific regards to the ways in which space is scanned, delineated, constructed, and paradoxically, overcome in crisis. We can see this logic at work throughout Blindness, wherein geographic coordinates as well as social nuclei are fractured and recongealed within the quarantine wards. The hospital landscape undergoes a spatial and hierarchal remapping, predominantly at the hands of the seeing (the doctor's wife) or the "already" blind, as in the case of the man in the neighbouring rival ward whose blindness is not an effect of the contagion, but is herded away into the hospital anyway. Unlike the infected patients thrown suddenly into a state of visual and spatial incapacitation, both the seeing doctor's wife and the "permanently" blind man are equipped with the tools to navigate the hospital wards and thus survive.

It is necessary here to consider more closely the figure of the architect, a figure imbued with authority, who choreographs the masses and thus manages chaos. Sharon Stockton diagnoses this "hero-engineer" character-one who makes his appearance in a host of modernist literature - as the figure (always male) who embodies "the convergence of individual vitality and authoritarian principles" (814) as well as violence and virility. His innate ability can be summed 
up as the power of manifestation; that is, he possesses - perhaps not unlike the doctors' wife- the "epic vision" (Stockton 815) to project the impossibly interior into the manifestly exterior.

At first glance, the urge might be to conflate Caden with the figure of the heroic architect; he indeed orders space and its simulacral reproduction. In one scene, he even directs his set builders to put up the "fourth wall," in effect, achieving what seems to be utter narrative/spatial containment and sealing his characters (both real and fictive) inside his mammoth warehouse set (Fig. 1). However, if to build is to maintain, to rationalise, and to dominate, Caden undoubtedly

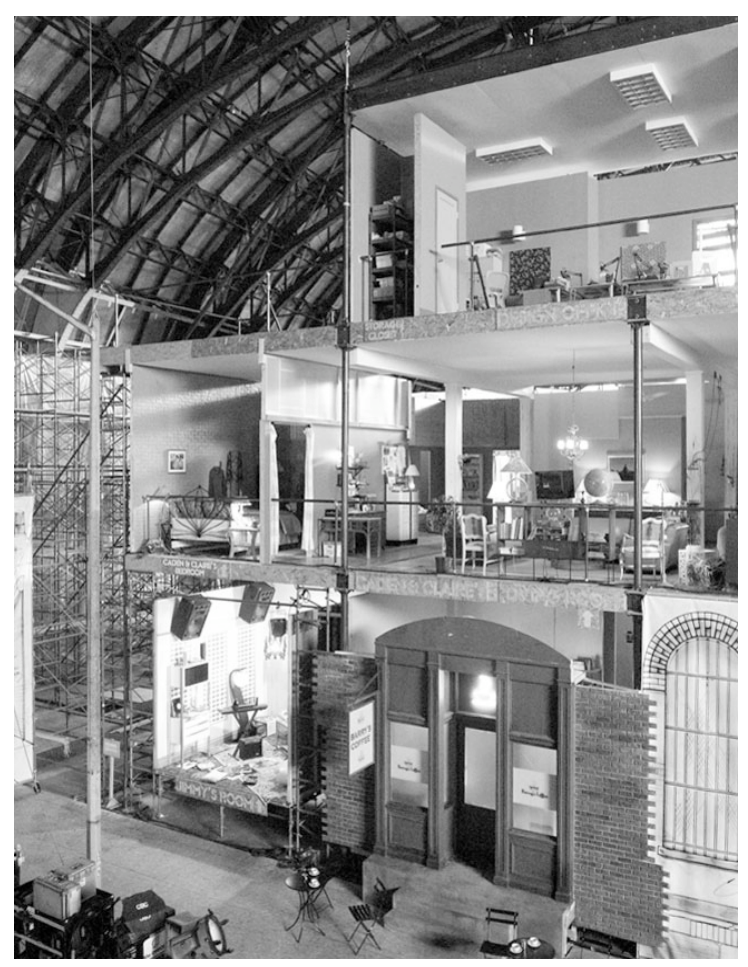

Fig. 1. Caden's warehouse set, Synecdoche, New York (2008)

fails. In his hands, the act of building is the compulsive corollary of narrative anxiety; he resorts to it when all else fails, just as he turns to the oasis of his warehouse repository as his world spins slowly out of control. His anxiety-ridden urge to build-up, to expand, to write-large is starkly contrasted to his estranged wife Adele's deft skill at painting miniatures—a skill which increases 
exponentially throughout the film, such that, by the end, she produces canvases so tiny they cannot be seen by the naked eye (Fig. 2). Adele embodies Gaston Bachelard's adept miniaturist, endowed with the ability to detach from the "jamming... waves" of the vast surrounding universe in order to (re)create and possess this world (161). Adele's capacity to produce the miniscule highlights for us Caden's tragic and ill-fated preoccupation with the gigantic. His warehouse city is so big that it bleeds into the real New York; it is a colossal replica, inside of which is contained an infinite chain of replica housed inside replica. Far from overcoming his structure, Caden is slipped under its creeping edge, and eventually swallowed whole.

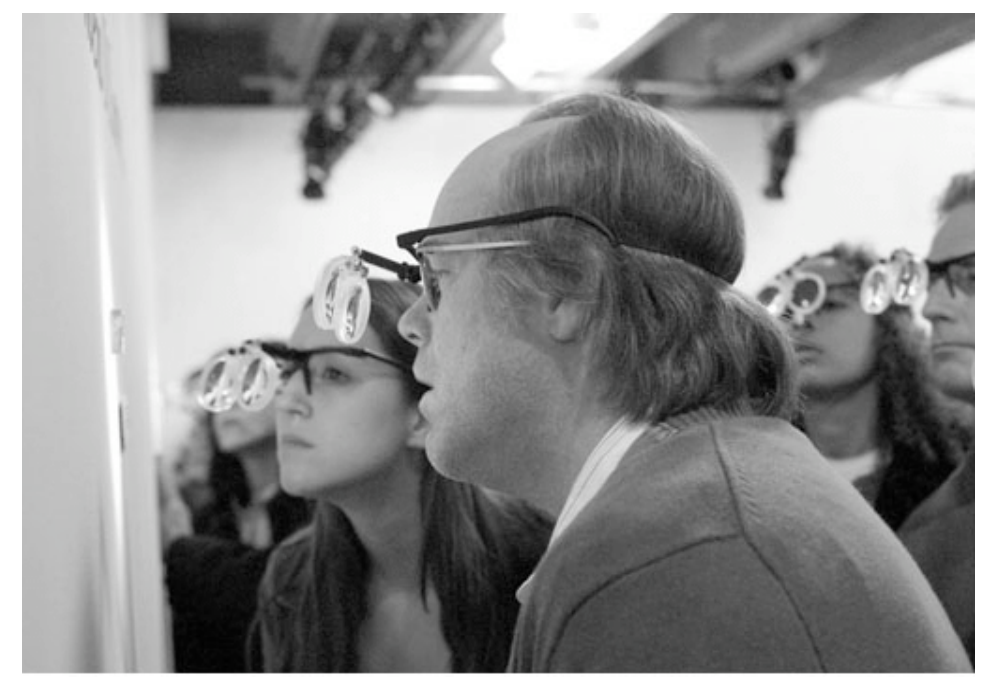

Fig. 2. Viewing Adele's miniature canvases, Synecdoche, New York.

In order to pause on the notion of allocating or "housing" crisis into a singular standing structure, it is useful to refer briefly to similar architectures of crisis pilfered from the annals of American history—and more specifically, New York history, which makes them particularly resonant in our this discussion of Synecdoche, New York. The first of the two examples are the infamous immigrant quarantines which existed along the New York harbour in one form or another for two centuries, from the mid 1700s to the mid 1900s. These quarantines, or "Plague Houses" as they were also called, were meant to intercept the waves of immigrants who were 
arriving in increasing droves on ships on the Hudson from mostly Eastern European countries, and feared to be carrying with them various infectious diseases such as cholera, small-pox and yellow fever. These plague houses were moved around from Liberty Island, Staten Island and various others - everywhere meeting with unhappy locals—-before city health officials finally realised that what was in fact needed was the creation of two artificial islands to house the infected ("Quarantine"). Hoffman, and Swinburne Islands (Fig. 3) were erected in the early 1870 's on completely reclaimed land, and remained quarantine stations for nearly five decades

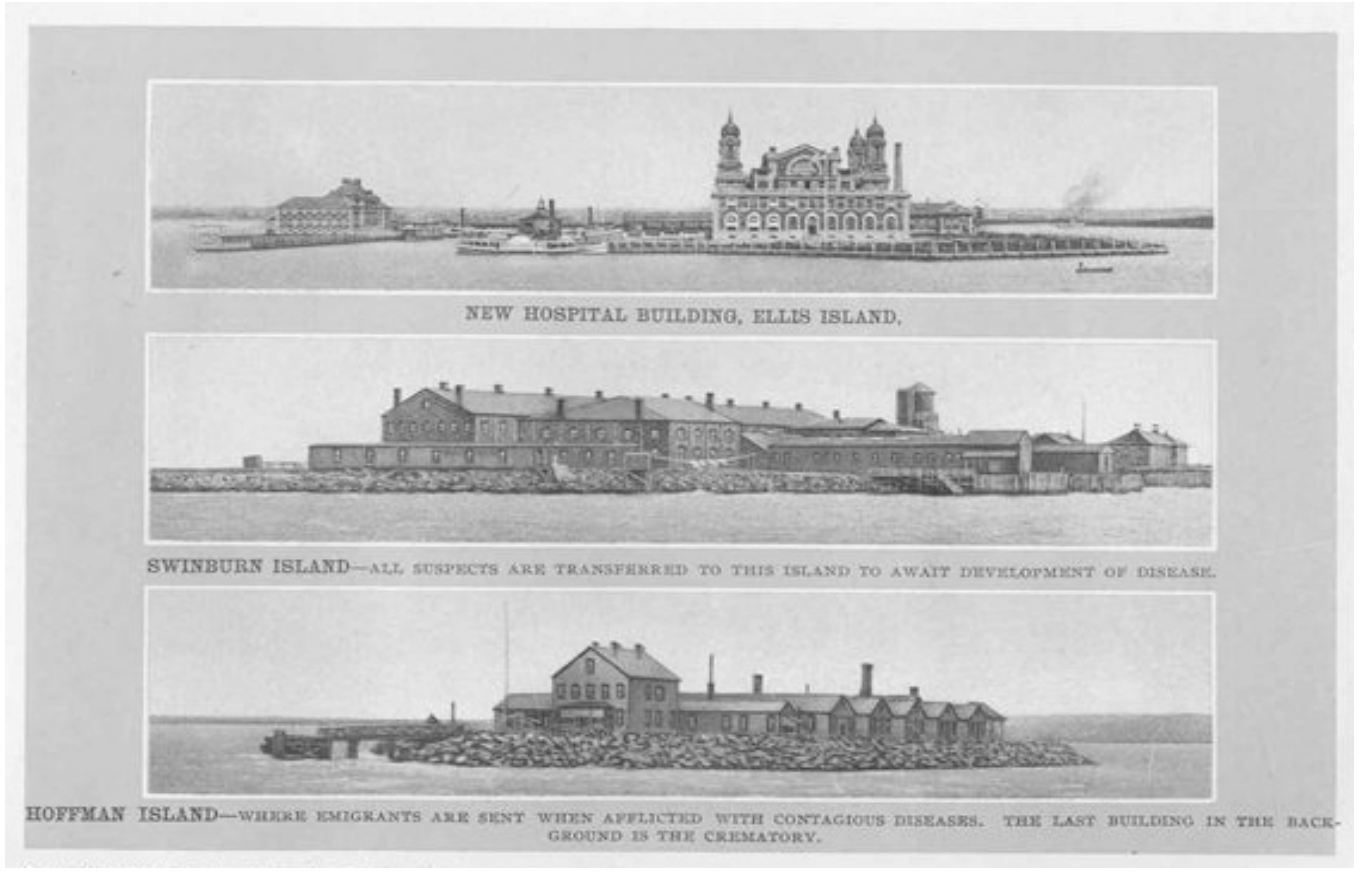

Fig. 3. View of three island quarantines: Ellis, Swinburne, and Hoffman. c. 1900 before they were closed down (Poole 143). This historical crisis motif re-emerges and in fact finds itself crystallized in Caden's own project. Both sets of quarantine architectures function precisely as the overwrought localization of crises, or the brick and mortar manifestations of collective anxieties. As such, they speak less about the "unruly" bodies being contained in them than about the powers that work so frantically and so compulsively to contain.

\section{Crisis Writing}


Parallel to the act of building, crisis writing reveals itself as the desire for narrative control and narrative coherence. Like the building of hermetic crisis architecture, writing enacts the rending of the (forcedly singular) trauma from its lineage of crisis in continuity. In Blindness, this figure of writing is structured both aesthetically and semantically with the film's tonal overexposure symbolizing the "blank page," and the need to (learn to) see and narrate anew. Lest one revert to the hasty optimism of some critics (Bono and Giardini; Zamora), however, the act of writing (or writing again), for our enquiry, is equated less with renewal than with discipline through sterilization. Again, we return to the idea that architectures of crisis-be they physical and/or discursive - often function to designate an abject space whose ultimate sublimation restores subsequently normative and untraumatized orders. As such, the figure of "blindness" here merely signals and carves out a space for the reassertion of disciplined and disciplinary "vision."

Both films privilege the omniscient narrator, although in Synecdoche, this privilege is of course highly provisional and even gently mocking in tone. We can temporarily accept Caden's role as "architect" of the story, if only to point out the divergences between his model and the comparatively unconflicted one found in Blindness. In both films, characters are, to a large degree, scripted representations, adding to the idea that these architectures exist in order that trauma can be rehearsed and effectively exer- or exorcised. The characters populating Synecdoche, while "real" to begin with, eventually slip into the netherworld of Caden's fictive construction; similarly, the characters in Blindness are nameless archetypes, with arguably no individual identity beyond their function in the larger design of crisis sublimation. Furthermore, their movements are seemingly choreographed through narration provided by "the old man with 
the eye patch," who not only narrates the actions inside the quarantine, but, through poetic illumination, provides a link between this world and the one on the outside.

As expected, authorial command is significantly troubled in Caden's story. His power over the text is haphazard at best. Time, for one, eludes him. In the breath of a single scene, "the beginning of fall" slides magically into Halloween, autumn mysteriously into winter. Half a century slips by in the span of what seems a month, and through it all, Caden remains as confounded as his audience, if also slightly uninterested in deciphering a temporal logic which exists outside and without him. As a director, Caden is also consumed exclusively with adapting and replicating; unlike Adele, he does not "create," but instead, compulsively recreates. Furthermore, even though it is on Caden's command that the replica city is built, he never possesses a privileged god's-eye perspective of it. Instead, he occupies the same space as de Certeau's walker in the city, who possesses none of the powers of the celestial eye, and whose view is the blind and groping one from "down below," amidst the thick and coiling texts of the unreadable city (de Certeau 93). Most revealing of Caden's forfeit of authorial reign, however, is towards the end of the film, when, tired and sad, he surrenders his own "role" to an actress previously playing Adele's cleaning lady, and consequently steps into hers. Ellen, the actress (now Caden the director) eventually directs Caden (now Ellen the cleaning lady) to his own death. Caden's death into the textual and architectural structure thus signals the literal death of the author (Barthes) — which is essentially his capitulation of authorial reign, and the surrendering of the his body to chaos and crisis.

The crisis architecture motif exemplified by the plague islands also finds resonances in a second historical example: the turn-of-the-century disaster spectacle. These elaborate spectacles were essentially the live re-enactments of crisis staged for huge audiences in places like Coney 
Island and other amusement parks around the country. These massively popular attractions usually involved recreations of natural disasters, like the eruption of Mt. Vesuvius and the Johnstown Flood. Most popular among these, however, was the fire spectacle. Drawing the most impressive crowds were Coney Island's "Fire and Flames" and "Fighting the Flames" (Fig. 4), both of which included casts of thousands of actors and professional firefighters, dramatically battling urban (usually tenement) fires (Dennett and Warnke). Their scripted narratives, argue Dennett and Warnke, made real disasters a "commonplace but thrilling event" (106), forever placating the audience with an abated fire at the end of each performance, and thus

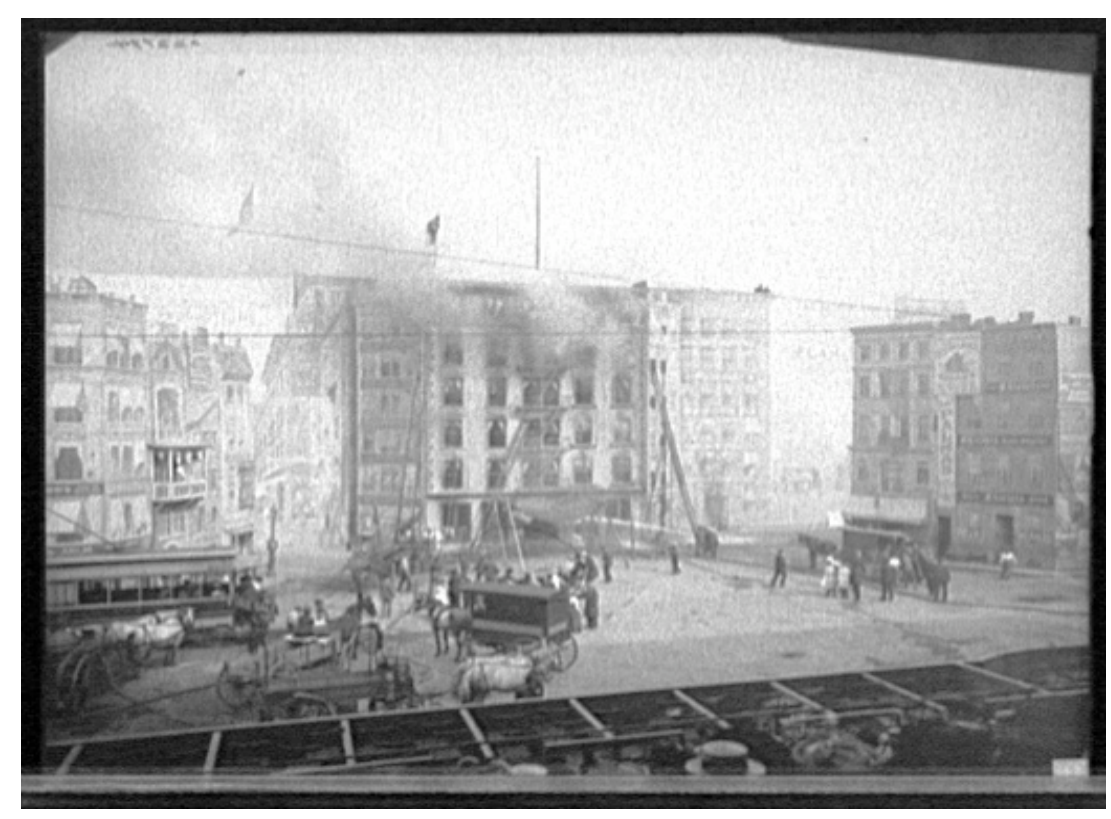

Fig. 4. "Fighting the Flames" fire spectacle at Coney Is., New York. 1905 providing them the "perpetual guarantee of safety" (107). An almost identical incarnation of the fire spectacle appears, eerily enough, in Synecdoche. Caden's love-interest, Hazel, moves into exactly such a burning house, which she manages to purchase for a steal, understandably, as it is in flames. The fundamental difference between Coney Island's burning house and Hazel's is that, while the fire spectacle has resolution and sublimation woven seamlessly into it, Hazel's fire is never put out. We revisit it at various points throughout the film, and watch as it continues 
to burn, and burn, decade after decade, offering no assurance that it will finally be extinguished in the end. In fact, the perpetual fire stands only to mock the presumptive tidiness of containment narratives and the self-satisfied authorial presence who attempts to provide their script.

To conclude, the hospital for the blind and Caden's warehouse can both be conceptualised as sites for the rehearsals of trauma, ultimately revealing the function of the quarantine to contain and supersede crisis and catastrophe. However, while the former manages to contentedly resolve its frictions, the latter lingers on a haphazard and ambivalent choreography of body, text, and architecture. Much like a mobius strip, Caden's structure defies the pretence of singularity and linearity, and does so in a beguilingly elliptical manner, in a way that foregrounds the compulsive striving to build, to write, to hold the self, against its corollary backdrop of defeat and collapse.

\section{Works Cited}

Bachelard, Gaston. The Poetics of Space: The Classic Look at How We Experience Intimate Places. Trans. Maria Jolas. Boston: Beacon Press, 1994.

Barthes, Roland. "The Death of the Author." Barthes, Roland. Image-Music-Text. Trans. Stephen Heath. New York: Hill and Wang, 1977. 142-148.

Blindness. Dir. Fernando Meirelles. Miramax. 2008.

Bono, Paola and Federica Giardini. "Crisis and Adventure." Signs 25.4 (2000): 10271031.

Certeau, Michel de. The Practice of Everyday Life. Trans. Steven Rendall. Berkeley: University of California Press, 1984.

Debord, Guy. Society of the Spectacle. Trans. Ken Knabb. Detroit: Black and Red, 1977. 
Dennett, Andrea Stulman and Nina Warnke. "Disaster Spectacles at the Turn of the Century." Film History 4.2 (1990): 101-111.

Poole, M. O. “Historic Islands at New York’s Front Door.” New York Times 28 Feb. 1937: 143. “Quarantine at New York.” HARPER'S WEEKLY: A Journal of Civilization 6 Sept. 1879: 704706.

Stockton, Sharon. "Engineering Power: Hoover, Rand, Pound, and the Heroic Architect." American Literature 72.4 (2000): 813-841.

Synecdoche, New York. Dir. Charlie Kaufman. Sony Pictures. 2008.

Zamora, Lois Parkinson. Writing the Apocalypse: Historical Vision in Contemporary U.S. and Latin American Fiction. Cambridge: Cambridge University Press, 1989. 